\title{
KERO-Playable Robotic Platform to Contribute to Non-verbal Communication Teaching in Children with Autism Spectrum Disorder
}

\author{
Tobar Q. Johanna ${ }^{\mathrm{a}, \mathrm{b},{ }^{*}, \text { Zaldumbide P. Alison }}{ }^{\mathrm{a}}$, Miranda L. Christian ${ }^{\mathrm{a}}$, Bacca C. Bladimir ${ }^{\mathrm{b}}$, \\ Caicedo B. Eduardo ${ }^{\mathrm{b}}$ \\ ${ }^{a}$ Department of Energy and Mechanical Sciences, Universidad de las Fuerzas Armadas ESPE, Sangolqui, 170501, Ecuador \\ ${ }^{b}$ School of Electrical and Electronic Engineering, Universidad del Valle, Cali, 76001, Valle del Cauca, Colombia \\ Corresponding author: "johanna.tobar@correounivalle.edu.co
}

\begin{abstract}
This work presents the design and construction of a recreational platform named KERO, which is oriented to the development of non-verbal communication skills in children with autism spectrum disorder (ASD) levels 1 and 2, between ages of 4 and 7 years old. The development of a friendly-looking robot with head and upper limbs movement is presented, which can perform 8 gestures such as: Cry, happy, Affirm, Deny, Say Hello, Exclaim, Quiet, Aim. KERO is a social robot that interacts with children with ASD through the usage of an intuitive interface. This interface allows proper interaction with the robot. In this interface, two games were developed to complement the robot-children interaction and increase their cognitive abilities by observing improvements in his/her attention, perception, memory, and problem-solving. The tests were validated under two different scenarios, preliminary and field tests, involving psychopedagogues, initial education students, therapists and children with ASD. Tests were carried out in a different number of sessions for each child. Each patient with ASD showed a different degree of social interaction with the KERO playable kit; their therapists evaluated this interaction during all sessions. At the end of the sessions with the patients, an improvement of $45 \%$ in recognition of gestures and $23.06 \%$ in the execution time of the memory game could be observed.
\end{abstract}

Keywords-Autism Spectrum Disorder (ASD); social robotics; non-verbal communication; robot-assisted therapy; teaching.

Manuscript received 16 Nov. 2020; revised 11 Feb. 2021; accepted 23 Feb. 2021. Date of publication 31 Aug. 2021. IJASEIT is licensed under a Creative Commons Attribution-Share Alike 4.0 International License.

\section{INTRODUCTION}

Technology has been used to develop therapies for children with Autism Spectrum Disorder (ASD). Treatment with technological environments offers fundamental information so that therapists can personalize the content depending on the needs of each patient. Researches in recent years help in the sensory problems of children with ASD using a controlled setting, mechanical toys, and robots [1].

According to Zusuki et al. [2], Children with ASD need an entertainment environment to get longer interaction with them. They used NAO dancing that could help in the learning of social skills. On the other hand, Alarfaj et al. [3] indicate that robotic technology can be useful to overcome disabilities in ASD therapy. Several studies have proved of great help to some children; however, there are no treatments that completely improve the symptoms or work for all children with ASD [4]. Van Straten et al. [5] discuss that not all robots can help treat children with ASD; the study shows that a robot's intonation and bodily appearance are essential specifications to implement on the robot. These characteristics can affect the child's mood and make the treatment easier. Boccanfuso et al. [6] developed a low-cost robot that is socially assistive, using games and a teleoperated mode. This work indicates that children with ASD get better in speech and social interaction and communication during the therapies.

Children with ASD may have communication deficits and difficulties in interaction with the surrounding environment. The work of Scassellati et al. [7] improves the social skills of a group of children, using an autonomous robot interacting with them for about 30 minutes in a one-month period, showing that robots can provoke proactive social behavior in children with ASD. Esteban et al. [8] propose a supervised autonomous system using robots to apply in the therapy of children with ASD. Also, it is mentioned that some ethical considerations have to be considered in the acceptance of robots in therapies for children with ASD, mentioning that a fully autonomous robot may not be good for these therapies. A study conducted by Petric et al. [9] developed a robot- 
assisted ASD diagnostic protocol. This is important because, in the future, the robot could track a child and observe its behavior in a more efficient way than a therapist.

The development of social and communication skills is generated in the first years of life. So, it is important to stimulate this type of skill from an early age. In a study carried by Ali et al. [10], an adaptive multi-robot therapy was implemented in 12 ASD children improving imitation skills and joint attention, helping to improve their social communications.

In a case study conducted by Huijnen et al., they used the KASPAR robot to analyze the strengths and weaknesses of using robots to interact with children with ASD. The study consisted of an interaction between the robot and a group of children through 6 different roles, based on each child's needs and the recommendation of the therapists. During the sessions, it was observed how the children react to each role shown by the robot. At the end of the investigation, it was concluded that the use of the KASPAR robot would have positive expectations in achieving specific goals in the treatment of children with Autism [11].

In many cases, therapies for ASD are time-consuming. Therefore, it is necessary to develop new evaluation methods such as the partially observable Markov decision process modeling (POMDP), which uses a robot to give an ASD diagnostic protocol. This type of process is useful in situations of uncertainty, as indicated by Petric et al. [12]. However, in other cases, conventional treatments provided by therapists are important because they have direct observation of behaviors of children with ASD. The advice of professionals in this area is important during the application of robots for the treatment of autism spectrum disorder. [13], [14].

Damianidou et al. [15] study the role of social robots like Probo models in assisting therapies with autistic children. This study indicates that Probo can recognize emotions in children and also show their own emotions. The tests indicate that using this type of robot can be effective in improving social skills in people with ASD.

A study carried out by Vlachou et al. [16] evaluates the effect of applying mobile technology in treatments of people with autism spectrum disorder and points out that there is great potential to develop autonomous mobile robots focused on young people with autism. These systems provide interactive environments and can offer a better life quality. Silvera-Tawil et al. [17] conducted a study on students with intellectual disabilities and autism after interacting with two humanoid robots. During this time, the students improved communication skills and helped improve the interaction of autism patients with their environment.

The proposed project is of great importance because it serves as a support tool for developing non-verbal communication skills of children with ASD. It consists of a robot that has memory games and a gesture identification game. The playful kit allows children to interact with technology and software; it contributes to the validation of knowledge acquired by the child through the therapies performed, providing a versatile device that can be used in both treatment centers for children with ASD and in every child's home.

\section{MATERIAL AND METHOD}

This section presents the different technical and social characteristics that were considered for the development of the "KERO" gaming platform, and the functionality of the robot is detailed.

\section{A. Therapeutic and technical requirements}

KERO is a robot kit designed to help to improve the learning of non-verbal communication skills of children with Autism Spectrum Disorder (ASD), aged between 4 to 7 years. The requirements and suggestions provided by therapists from the CERENI Neuropsychological Rehabilitation Center are listed below:

- To avoid screws or surfaces that could hurt the child.

- To paint the robot with light colours or pastels.

- Do not place more than 6 pairs of cards in the memory game.

- To activate sounds for each successful task.

- To place images of characters with whom the child is attracted (superheroes, animals, etc.)

- To develop in the native language of the children of the target population (Spanish).

In addition, other considerations must consider improving the effectiveness of the tool; among them, we have: the robot must be reprogrammable, robust, affordable, and must offer options in its games [18]. A Gaming Platform was made with a white human-like robot to meet these specifications, with 8 degrees of freedom, 2 for head movement, and 6 for upper limb movements. Finally, KERO has two games that allow it to interact with children with ASD: one consisting of a memory game to choose pairs of cards and a second game to improve visual attention, where the child must recognize the gesture made by the robot.

\section{B. KERO design}

This section describes the design and operation of the Playable Kit KERO and the reasons why each element of the system was implemented.

1) External Appearance: A robot capable of human-like movements and a child-friendly appearance was designed. This was considered because, as Mori [20] stated, there is a relationship between human similarity and the familiarity, sympathy, or comfort felt in the presence of an individual or object, in this case, the KERO robot in Fig. 1).

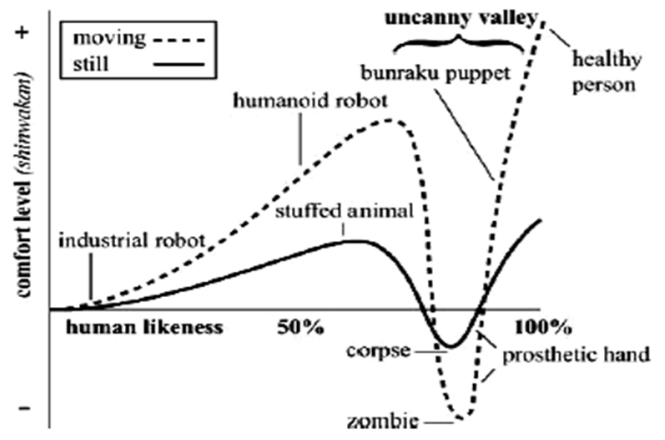

Fig. 1 Graphic of the uncanny valley [19]

In Fig. 1, Mori describes that this comfort remains stable until a point is reached where robots tend to appear so close 
to humans that even the smallest imperfections can make them look unsettling. This feature is called the Uncanny Valley. Due to this uncanny valley, it was decided to make a robot like a human, taking care of aspects that prevent the robot from causing fear or confusion in children with autism.

2) Materials and Components: Fused Deposition Modeling (FDM) was used to make the robot structure. The material is chosen to make the robot polylactic acid (PLA) because it is not a toxic material and is friendly to the environment as it is biodegradable. The PLA has a consistent structure, easy to use, and gives a smoother and brighter appearance to the robot, obtaining more detail. In addition, it was evaluated that the mechanical properties of PLA (Table 1) allow the robot to be more robust.

TABLE I

MEChaniCAL AND Physical PROPERTIES OF PLA [21]

\begin{tabular}{lr}
\hline \multicolumn{1}{c}{ Property } & \multicolumn{1}{c}{ Dimension } \\
\hline Elastic modulus & $3500[\mathrm{MPa}]$ \\
Density & $1.25\left[\mathrm{~g} / \mathrm{cm}^{\wedge} 3\right]$ \\
Young's modulus & $1280[\mathrm{MPa}]$ \\
Tensile strength & $59[\mathrm{MPa}]$ \\
Elongation at break & $7 \%$ \\
Specific heat $\left(55^{\circ} \mathrm{C}\right)$ & $1590\left[\mathrm{~J} / \mathrm{kg}-{ }^{\circ} \mathrm{C}\right]$ \\
Melt density & $1.07\left[\mathrm{~g} / \mathrm{cm}^{\wedge} 3\right]$ \\
Ultimate tensile strength & $73[\mathrm{MPa}]$ \\
Thermal conductivity $\left(48^{\circ} \mathrm{C}\right)$ & $0.11\left[\mathrm{~W} / \mathrm{m}^{\circ}{ }^{\circ} \mathrm{K}\right]$ \\
\hline
\end{tabular}

To build the base and the wireless controller of the robot, $4 \mathrm{~mm}$ thick Acrylic / PMMA was used because it is a resistant, light and easy to transport material. Laser cutting was used to manufacture each support and sides of the base. This tool was used due to its high precision, it also allows for round finishes, and it does not require any further processing.

The Kero Playable kit will have a set of components that will allow the robot to interact in an optimal way, depending on the therapy and the child's preferences. In this way, the KERO Playable Kit will be made up of several components, as shown in Fig. 2, and they are listed below:

- KERO robot (Fig. 2A).

- Robot base (Fig. 2B).

- Box for transporting the robot (Fig 2C).

- Clay set (Fig 2D).

- Wireless controller (Fig 2E)

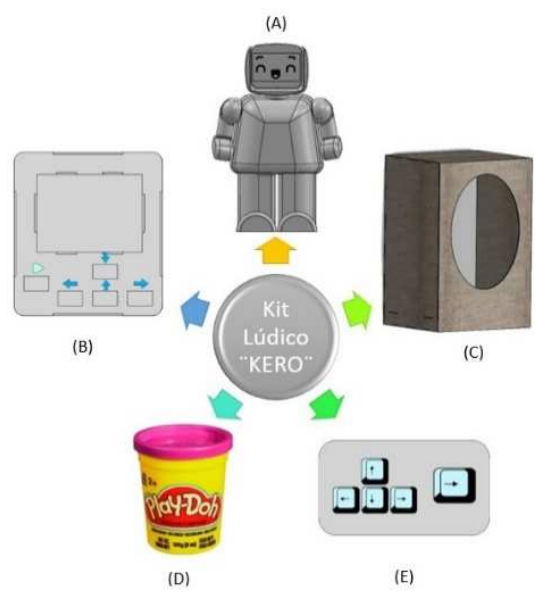

Fig. 2 Components of the Playful Kit
An important feature of the KERO playable kit is the possibility of replacing the buttons on the wireless controller for the robot with buttons that children can create with everyday items such as play Doh clay, leaves or petals. The robot base (Fig. 3) is adapted to place the direction arrow buttons and a selection button.

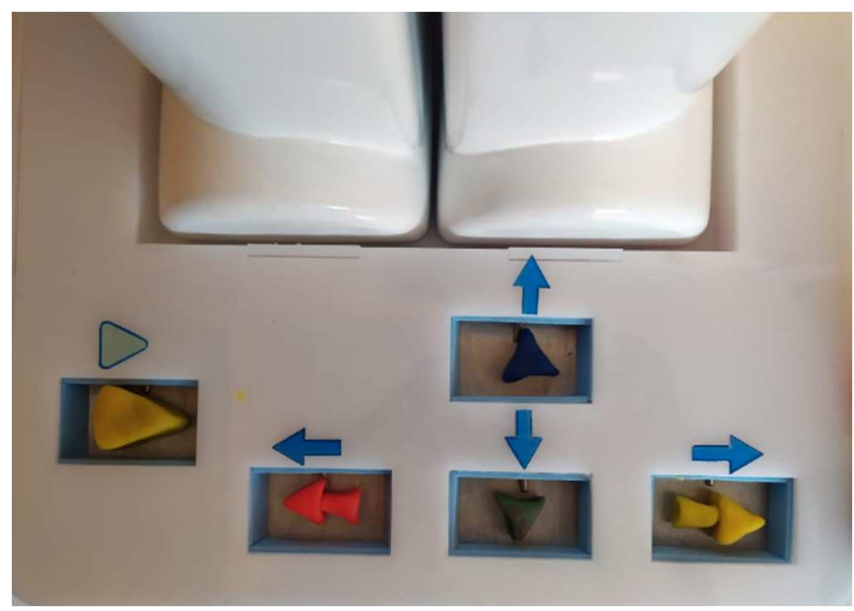

Fig. 3 Using modeling clay as an input peripheral.

3) Gestures and Movements: The robot will be able to perform 8 different gestures through movements of both the head and movements of the upper extremities. Each movement is carried out in a uniform way, avoiding rough or sudden actions that disturb the child. Next, each gesture is explained with the respective movement made by the robot, as in Fig. 4.

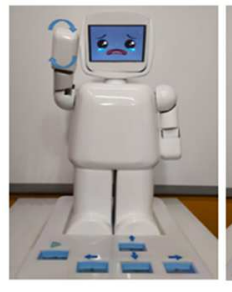

(A)

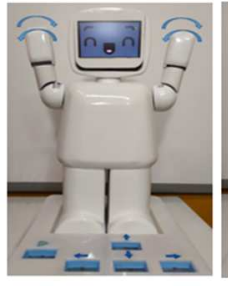

(E)

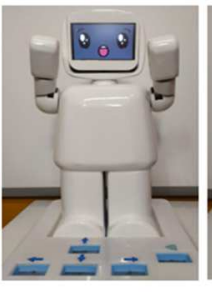

(B)

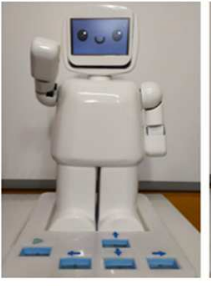

(F)

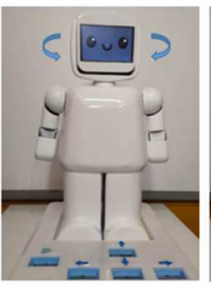

(C)

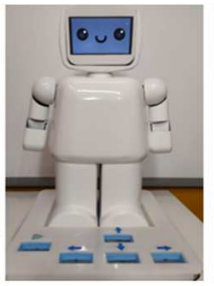

(G)

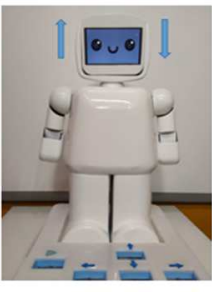

(D)

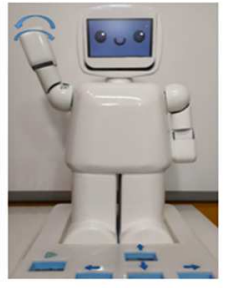

(H)
Fig. 4 Gestures made by the robot

These gestures are described as follows:

- Crying: In this gesture, the robot raises the upper right limb towards the head, the head moves slightly downwards and the arm moves back and forth while a sad face with tears in the eyes appears on the screen (Fig. 4A).

- Scared: The robot raises its 2 limbs towards the head, and the screen shows a scared gesture with its mouth open (Fig. 4B).

- No: The robot moves its head from one side to the other several times, and the screen shows a neutral gesture. (Fig. 4C).

- Yes: The robot moves its head back and forth several 
times, and the screen shows a neutral gesture (Fig. 4D).

- Cheerful: The robot raises both upper limbs above the head, shaking slightly to the sides. The screen shows an open-mouthed smile gesture (Fig. 4E).

- Pointing: The robot raises its right upper limb to shoulder height and leaves it in a horizontal position for about 3 seconds. The display shows a neutral (Fig. 4F).

- Calm: The robot raises the arms slightly above the waist for about 3 seconds. The screen shows a neutral gesture (Fig. 4G).

- Greet: The robot raises its right upper limb above its head and moves from left to right several times. The screen shows a neutral gesture (Fig. 4H).

\section{Game Description}

The screen has an attractive and easy-to-use environment for children with ASD. Light colors and pastel tones were used since it is a requirement; following these aspects, two games were developed:

1) Pair of Cards Game: The first game consists of finding the pair of cards of the same figure from a set of cards. The game will have 2, 3, 4 and 6 pairs of cards (Fig. 5), depending on the memory capacity of each child with ASD.

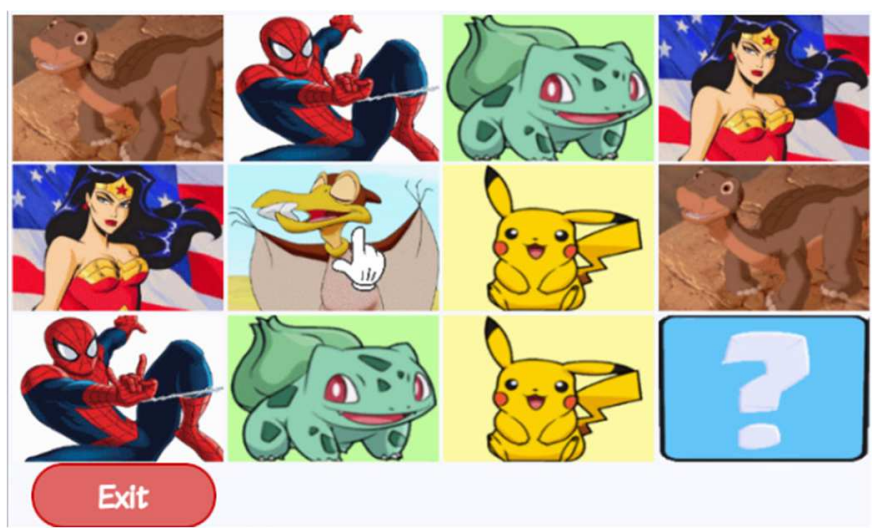

Fig. 5 Card pairs game interface.

2) Recognize the Robot's Gesture:The second game consists in that the child must identify the gesture made by the robot and select it on the screen (Fig. 6). In case the child fails, they have the option to try again, until the child get it right.

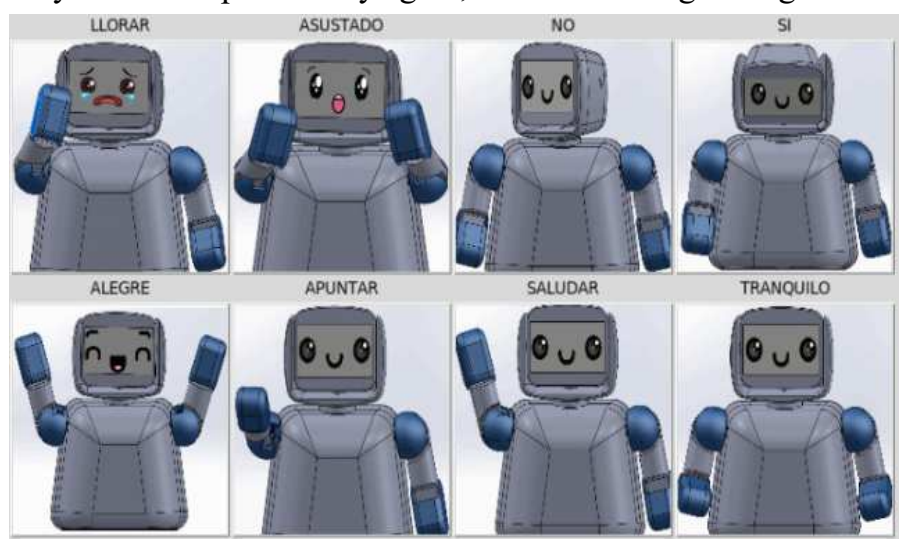

Fig. 6 Gesture game interface.

\section{KERO Software GUI}

The KERO playable kit can be operated in 2 ways: the first will be through the use of a wireless controller, which will have 4 directional buttons to move the cursor and a selection button. The second will be with the use of everyday objects such as clay, which will replace the wireless controller for handling the robot. See Fig. 7.

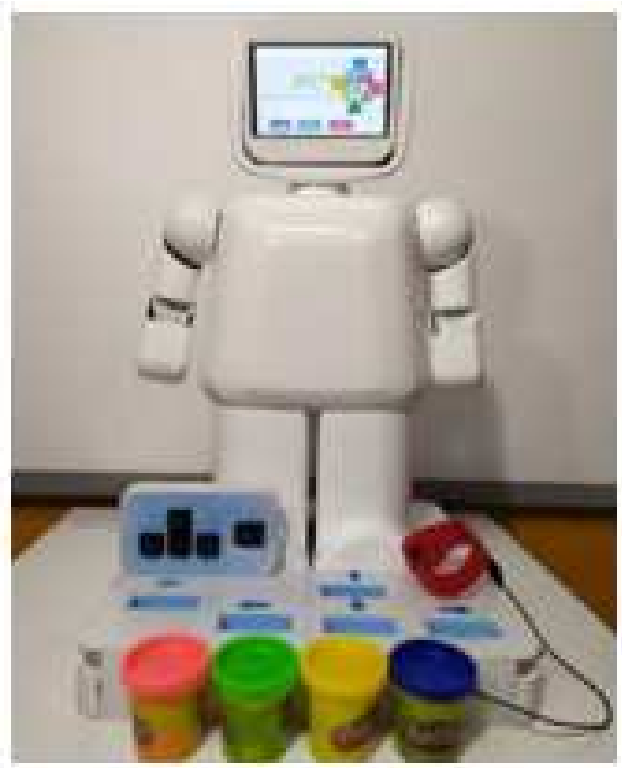

Fig. 7 Playful Kit

Once the robot has been turned on, the main menu will be displayed (Fig. 8). With the "A" button, the memory game is selected, with the "B" button the game of recognizing the gesture, and with the "C" button, the robot is switched off.

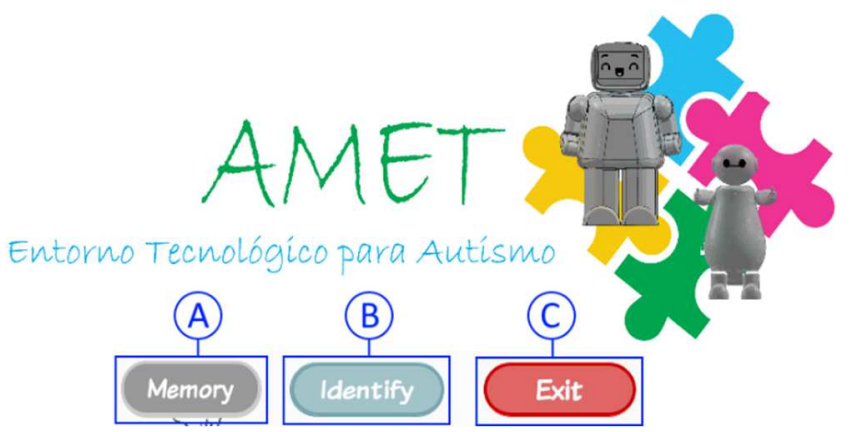

Fig. 8 Starting screen

With the "A" button, a screen is displayed where the type of memory cards must be selected (Fig. 9). You can choose between two types of cards: animated character cards (Button "D") and emotion cards (Button E). Once the type of card has been selected, a screen will open to choose the number of pairs of cards (Fig. 10). Subsequently, the memory game screen is displayed with the number of pairs selected (Fig. 11). With the "F" button, you can exit the game and go to the main menu. The memory game is over once all pairs of cards have been discovered.

\section{Select a topic.}

(D)

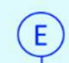

Animated

Emotions

Fig. 9 Card type selection screen 


\section{Select the number of pairs}

\section{2}
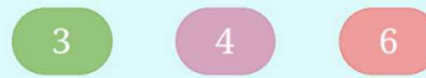

Fig. 10 Card number selection screen
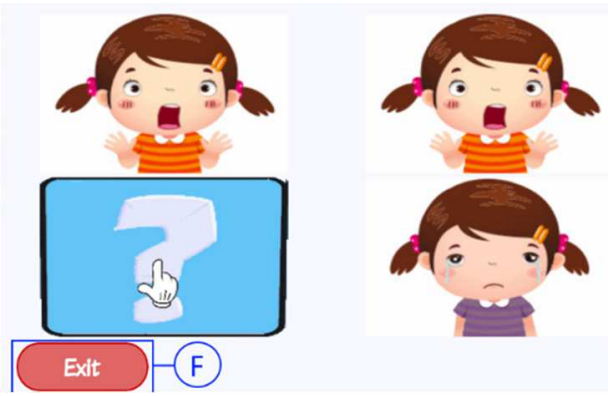

Fig. 11 Card game screen

Back to the main activity shown in Fig. 8, using the "B" button, the gesture identification set is selected. Once the "B" button has been pressed, the robot proceeds to perform one of the 8 programmed gestures. When the robot finishes making the movement, a screen is displayed where the child must select the gesture made by the robot (Fig. 12). If the child chooses the gesture wrongly, the game indicates the option to try again or exit to the main menu (Fig. 13). The game ends once the child has correctly identified the gesture made by the robot.

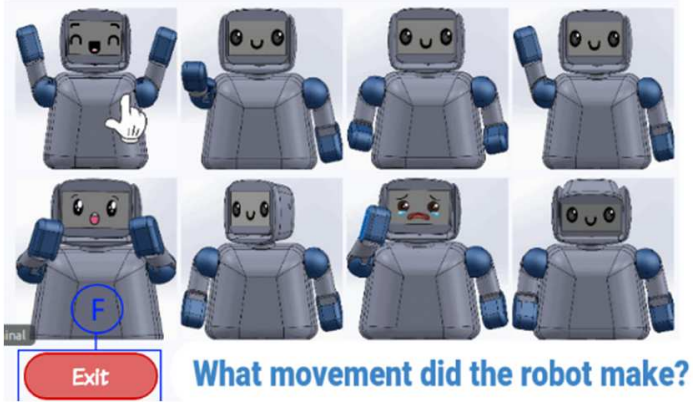

Fig. 12 Gesture recognition game screen

\section{Do you want to try agaln?}

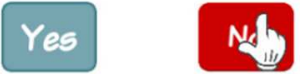

Fig. 13 Screen again attempt of the game to recognize gestures

At the end of any of the two games, the robot proceeds to make a gesture of joy accompanied by motivating sounds as positive reinforcement for the child for having performed the task successfully.

\section{RESULTS AND DISCUSSION}

KERO was validated under two different scenarios: preliminary tests and field tests, each of which is described in this section.

\section{A. Preliminary Tests}

To validate the tool before testing it in the target population, preliminary tests were carried out on two groups of people described below:

- Group A: 12 Psychopedagogues.

- Group B: A group of 23 initial education students.

The presentation of the operation of the KERO Playable Kit was made virtually due to the global health emergency and the confinement by Covid 19. Using multimedia tools, the characteristics and operation of the KERO Playable Kit were shown. A survey was conducted on each group of people; the questions are described in (Table 2).

TABLE II

EVALUATION FORMAT FOR PRELIMINARY TESTS

\begin{tabular}{|c|c|c|}
\hline No. & Question & Rating Scale \\
\hline 1 & $\begin{array}{l}\text { How attractive do you think the tool has } \\
\text { been for children? }\end{array}$ & $\begin{array}{l}1 \text { Not attractive } \\
2 \text { Unattractive } \\
3 \text { Attractive } \\
4 \text { Very attractive }\end{array}$ \\
\hline 2 & $\begin{array}{l}\text { During the session, do you consider that } \\
\text { the use of the Play Kit helps to improve } \\
\text { the child's non-verbal communication } \\
\text { skills? }\end{array}$ & $\begin{array}{l}\text { YES and NO } \\
\text { question }\end{array}$ \\
\hline 3 & $\begin{array}{l}\text { Do you consider that in the country } \\
\text { there are few technological } \\
\text { environments to help the teaching and } \\
\text { learning of non-verbal communication } \\
\text { skills of the child? }\end{array}$ & $\begin{array}{l}\text { YES and NO } \\
\text { question }\end{array}$ \\
\hline 4 & $\begin{array}{l}\text { Do you consider that the Playful Kit is } \\
\text { an innovative tool for teaching gestures? }\end{array}$ & $\begin{array}{l}\text { YES and NO } \\
\text { question }\end{array}$ \\
\hline 5 & $\begin{array}{l}\text { During the session, do you think the } \\
\text { child would show interest in the Play } \\
\text { Kit? }\end{array}$ & $\begin{array}{l}\text { YES and NO } \\
\text { question }\end{array}$ \\
\hline 6 & $\begin{array}{l}\text { During the session you consider that the } \\
\text { Playful Kit can be a contribution in the } \\
\text { education of gesture reinforcement. }\end{array}$ & $\begin{array}{l}\text { YES and NO } \\
\text { question }\end{array}$ \\
\hline 7 & $\begin{array}{l}\text { During the session, do you consider that } \\
\text { the child will reinforce his memory } \\
\text { through the game of pairs of the Playful } \\
\text { Kit. }\end{array}$ & $\begin{array}{l}\text { YES and NO } \\
\text { question }\end{array}$ \\
\hline 8 & $\begin{array}{l}\text { How many cards do you consider to be } \\
\text { adequate in the Playful Kit pairs game } \\
\text { for the correct development of the } \\
\text { memory of a child between } 5 \text { and } 7 \\
\text { years old. }\end{array}$ & $\begin{array}{l}\text { Selection } \\
3 \text { pairs } \\
4 \text { pairs } \\
6 \text { pairs } \\
9 \text { pairs }\end{array}$ \\
\hline 9 & $\begin{array}{l}\text { During the session, you consider that } \\
\text { the child can improve his attention with } \\
\text { the game of recognizing the robot's } \\
\text { gesture }\end{array}$ & $\begin{array}{l}\text { YES and NO } \\
\text { question }\end{array}$ \\
\hline 10 & $\begin{array}{l}\text { Do you consider that the use of } \\
\text { elements such as leaves, fruits, and } \\
\text { plasticine to manipulate the robot, } \\
\text { improves the learning experience and } \\
\text { interaction with the Playful Kit? }\end{array}$ & $\begin{array}{l}\text { YES and NO } \\
\text { question }\end{array}$ \\
\hline 11 & $\begin{array}{l}\text { Do you consider that the child's parents } \\
\text { would be willing to acquire this Playful } \\
\text { Kit as a toy and a means of } \\
\text { development for the child? }\end{array}$ & $\begin{array}{l}\text { YES and NO } \\
\text { question }\end{array}$ \\
\hline
\end{tabular}

Question 1 is based on the modified Likert scale [22]; the following notations are considered: Not at all attractive (N.A), 
Unattractive (U), Attractive (A) and Very Attractive (V.A). The results of group A and B surveys are shown in (Table 3), (Table 4) and (Table 5).

TABLE III

RESUlTS OF QUESTION 1 FOR GROUP A AND B

\begin{tabular}{lllll}
\hline $\begin{array}{l}\text { Question } \\
\text { No. }\end{array}$ & N.A & U & A & V.A \\
\hline 1 & 1 & 3 & 8 & 24 \\
\hline
\end{tabular}

RESUlTS OF QUESTIONS 2,3,4,5,6,7,9 AND 11 FOR GROUP A AND B

\begin{tabular}{lll}
\hline Question No. & Yes & No \\
\hline 2 & 35 & 1 \\
3 & 35 & 1 \\
4 & 34 & 2 \\
5 & 35 & 1 \\
6 & 34 & 2 \\
7 & 35 & 1 \\
9 & 33 & 3 \\
10 & 31 & 5 \\
11 & 29 & 7 \\
\hline
\end{tabular}

TABLE $\mathrm{V}$

RESULT OF QUESTION 8 FOR GROUP A AND B

\begin{tabular}{llllc}
\hline $\begin{array}{l}\text { Question } \\
\text { No. }\end{array}$ & $\begin{array}{l}\text { 6 cards } \\
\text { (3 pairs) }\end{array}$ & $\begin{array}{l}\text { 8 cards } \\
\text { (4 pairs) }\end{array}$ & $\begin{array}{l}\text { 12 cards } \\
\text { (6 } \text { pairs) }\end{array}$ & $\begin{array}{l}\text { 18 cards } \\
\text { (9 pairs) }\end{array}$ \\
\hline 8 & ---- & 14 & 21 & 1 \\
\hline
\end{tabular}

According to the results obtained in questions 2 and 4, it is observed that the two groups agree that the use of the KERO Playable Kit helps in the improvement of the child's nonverbal communication skills because it is an innovative tool, it is easy to use and has elements that can be added as input peripherals, and that can attract the attention of the child with ASD. Also, when analyzing the answers to questions 6,7 and 9 , it is concluded that the two groups of people think that the KERO robot can help develop memory, visual attention, and considering that the kit can make it possible a contribution to the education of gestures.

In question 8, group A prefers the use of 6 pairs of cards to be implemented in the game for children between 4 and 7 years old, while group B presented two modes that are 4 and 6 pairs of cards for this game, obtaining a median of 5 pairs. In question 5 , both groups $\mathrm{A}$ and $\mathrm{B}$ consider that the child will show interest in the KERO playable kit because $97 \%$ of the respondents answered yes. In question 2, both groups A and $\mathrm{B}$ consider that using the KERO playable kit helps improve the child's non-verbal communication skills because $97 \%$ of the respondents answered yes.

\section{B. Field Tests}

For the second scenario, a series of field tests were carried out with previously established experimental subjects; The operation of the KERO Playable Kit was presented and implemented in-person for children with ASD at the CERENI Neuropsychological Rehabilitation Center. A field test was carried out in Quito-Ecuador with the pediatric population diagnosed with Autism Spectrum Disorder, who regularly attend the Neuropsychological Rehabilitation CenterCERENI.
CERENI is a rehabilitation center that provides diagnosis, treatment, and rehabilitation of people with diseases of the nervous system, which can be acquired or developed, both in adults and children; thus, allowing them to access a complete and coordinated treatment in one place. Currently, the treatments performed by therapists at CERENI for children with ASD are traditional.

1) Subjects: The subjects tested during the experiments belong to the CERENI pediatric population. The therapies were developed with four children diagnosed with Autism Spectrum Disorder. Therapists selected the children participating in the experiments from the rehabilitation center after obtaining informed consent from each child's parents or legal guardians.

2) Ethical Considerations: The experimental procedure was carried out according to the recommendations approved by the ethics committee of the Universidad del Valle, issued in the ap-proved document 003-020.

3) Experimentation: The experimentation process consisted of testing and using the robot by children with ASD in a period of approximately 1 month; the tests were carried out in different sessions, lasting approximately 30 minutes for each child.

During the first sessions, work was done on familiarizing the child with the robot and with the researchers present in each test. The children were admitted together with their therapists to the testing room. Subsequently, a researcher oversaw the gesture recognition game for the child to observe the robot's movements and thus capture their attention (Fig. 14). Once the child became interested in the robot and tried to interact with it, he was told how the robot works and, in case the child allows more interaction; he was allowed to use the wireless controller and the clay-based controller (Fig. 15).

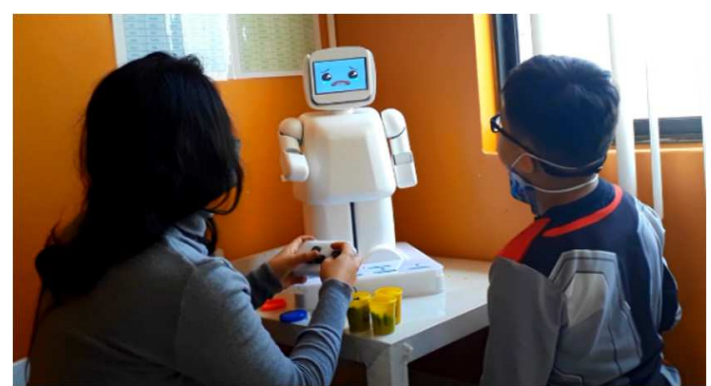

Fig. 14 Field test 1 with an experimental subject, conducted on July 30, 2020.

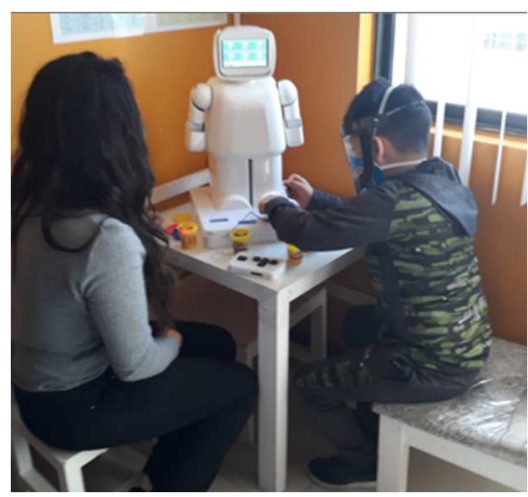

Fig. 15 Field test 1 with an experiment subject using plasticine, carried out on July $30,2020$. 
In later sessions, the child could use the robot without any help, as they adapted to the operation and logic of each KERO game (Fig. 16). In this scenario, the effects of the robot to aid memory and visual attention of each child were observed.

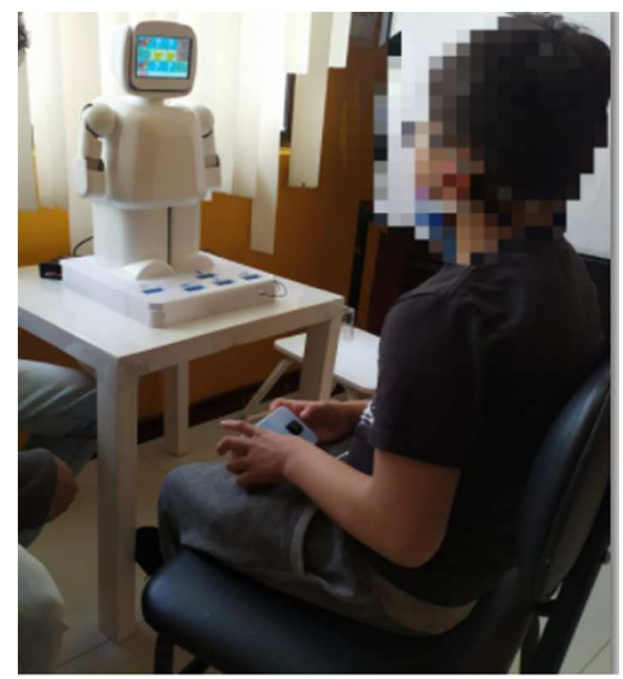

Fig. 16 Field test 1 with an experiment subject using plasticine, carried out on July 30, 2020.

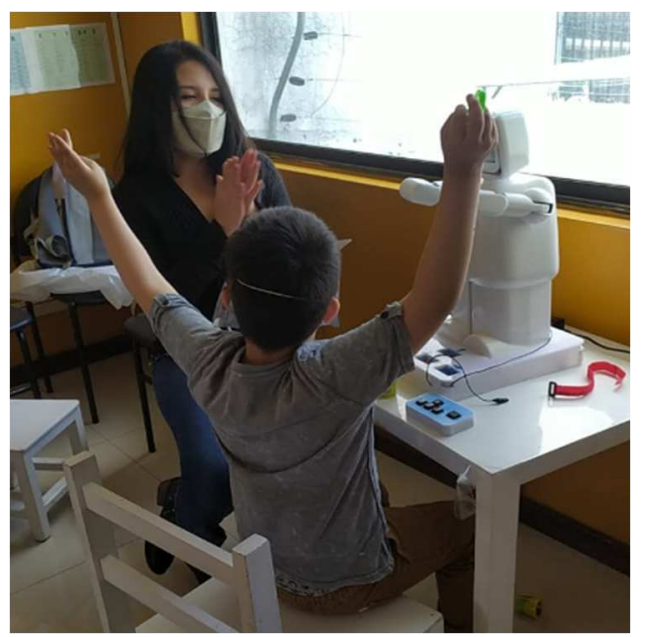

Fig. 17 Subject of experiment imitating the movements of the robot, carried out on August 7, 2020

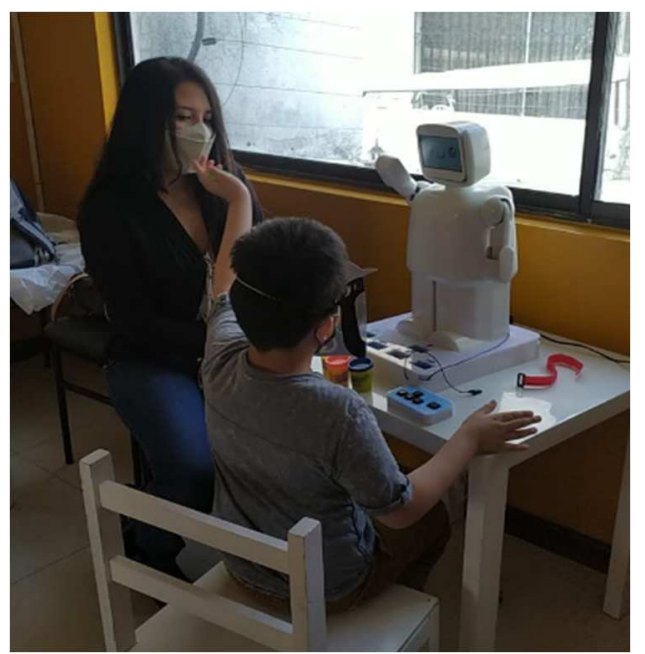

Fig. 18 Experiment subject imitating the movements of the robot, carried out on August 7, 2020

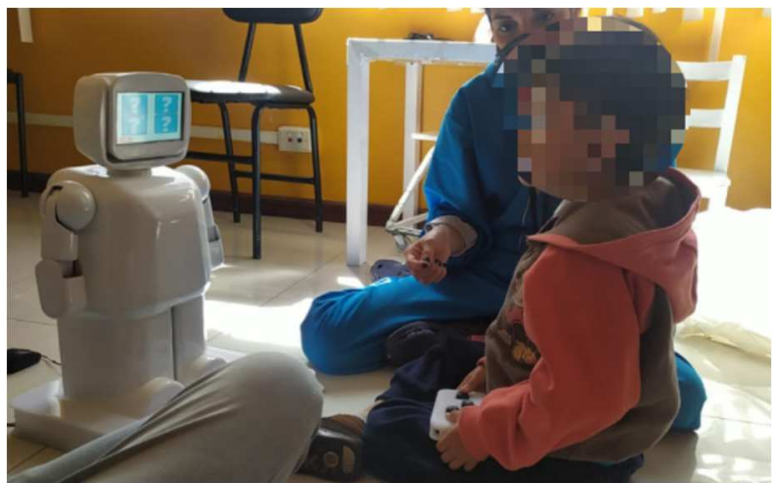

Fig. 19 Experiment subject using the wireless control

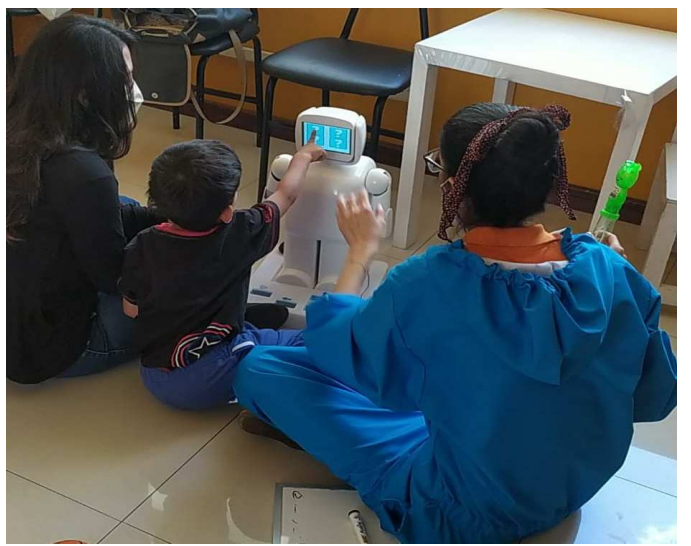

Fig. 20 Subject of experiment together with the therapist, carried out on August 5, 2020

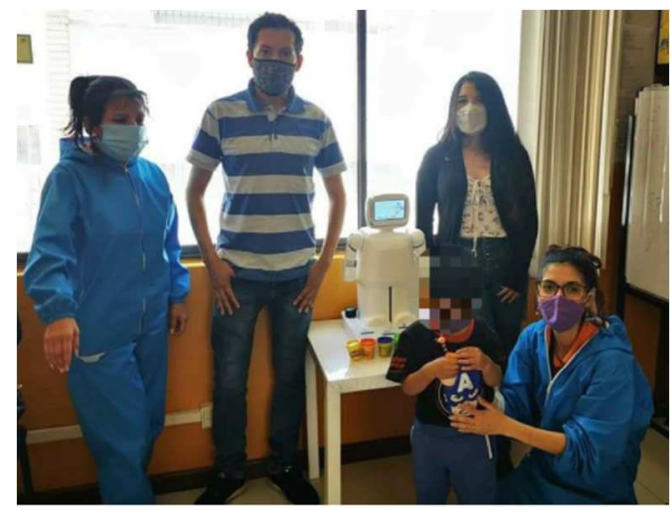

Fig. 21 Therapists present during field tests in children with ASD.

The children showed an interest in certain elements of the robot (Figures 17-20) that will be described based on the results of the surveys carried out. Fig. 21 shows the therapists who were present during the tests in children with ASD. Due to the current confinement situation, not all the children were able to attend their therapies on a regular basis, obtaining different number of sessions for each child, which are described below:

With the first child, who has grade 1 ASD (Patient 1), 6 sessions were carried out, in which the gesture recognition game, the memory game were performed and also managed to imitate most of the gestures that the robot performed. In the case of the second child, who has grade 1 ASD (Patient 2), 6 sessions were carried out, in which the gesture recognition game and the memory game were performed. Finally, the children corresponding to Patient 3 and Patient 4 of grade 2 
and 3, respectively, 4 sessions were carried out, in which the gesture recognition game and the memory game were performed.

4) Field Test Results: The degree of social interaction that each child with ASD showed with the use of the KERO playable kit was evaluated by their therapists during all sessions. The evaluations were carried out with the use of a survey, detailed in Table 6.

TABLE VI

EVALUATION FORMAT FOR CHILDREN WITH ASD

\begin{tabular}{|c|c|c|}
\hline No & Question & Rating Scale \\
\hline 1 & $\begin{array}{l}\text { In } 5 \text { attempts made with the game to } \\
\text { recognize the robot's gesture, how } \\
\text { many times did the child hit the YES } \\
\text { gesture. }\end{array}$ & $\begin{array}{l}\text { Value between } 0 \\
\text { and } 5\end{array}$ \\
\hline 2 & $\begin{array}{l}\text { In } 5 \text { attempts made with the game to } \\
\text { recognize the robot's gesture, how } \\
\text { many times did the child hit the NO } \\
\text { gesture. }\end{array}$ & $\begin{array}{l}\text { Value between } 0 \\
\text { and } 5\end{array}$ \\
\hline 3 & $\begin{array}{l}\text { In } 5 \text { attempts made with the game to } \\
\text { recognize the robot's gesture, how } \\
\text { many times did the child hit the CRY } \\
\text { gesture. }\end{array}$ & $\begin{array}{l}\text { Value between } 0 \\
\text { and } 5\end{array}$ \\
\hline 4 & $\begin{array}{l}\text { In } 5 \text { attempts made with the game to } \\
\text { recognize the robot's gesture, how } \\
\text { many times did the child hit the } \\
\text { SCARED gesture. }\end{array}$ & $\begin{array}{l}\text { Value between } 0 \\
\text { and } 5\end{array}$ \\
\hline 5 & $\begin{array}{l}\text { In } 5 \text { attempts made with the game of } \\
\text { recognizing the robot's gesture, how } \\
\text { many times did the child hit the } \\
\text { HAPPY gesture. }\end{array}$ & $\begin{array}{l}\text { Value between } 0 \\
\text { and } 5\end{array}$ \\
\hline 6 & $\begin{array}{l}\text { In } 5 \text { attempts made with the game to } \\
\text { recognize the robot's gesture, how } \\
\text { many times did the child hit the } \\
\text { POINTING gesture. }\end{array}$ & $\begin{array}{l}\text { Value between } 0 \\
\text { and } 5\end{array}$ \\
\hline 7 & $\begin{array}{l}\text { In } 5 \text { attempts made with the game to } \\
\text { recognize the robot's gesture, how } \\
\text { many times did the child hit the } \\
\text { gesture of GREETING. }\end{array}$ & $\begin{array}{l}\text { Value between } 0 \\
\text { and } 5\end{array}$ \\
\hline 8 & $\begin{array}{l}\text { In } 5 \text { attempts made with the game to } \\
\text { recognize the robot's gesture, how } \\
\text { many times did the child hit the } \\
\text { QUIET gesture. }\end{array}$ & $\begin{array}{l}\text { Value between } 0 \\
\text { and } 5\end{array}$ \\
\hline 9 & $\begin{array}{l}\text { During therapy, which control } \\
\text { element do you consider the child } \\
\text { showed the greatest interest in } \\
\text { manipulating the robot. }\end{array}$ & $\begin{array}{l}\text { Wireless control } \\
\text { or modeling } \\
\text { clay }\end{array}$ \\
\hline 10 & $\begin{array}{l}\text { During therapy, indicate the times in } \\
\text { which the patient manages to solve } \\
\text { the pairs game in each attempt. }\end{array}$ & $\begin{array}{l}\text { Number of pairs } \\
\text { of cards and } \\
\text { time. }\end{array}$ \\
\hline
\end{tabular}

Based on the responses to each survey, graphs were obtained to evaluate the impact of the KERO playable kit on each child with ASD. In questions 1 to 8 , the number of correct answers in 5 attempts is evaluated when identifying a certain gesture. To analyze the results of these questions, linear graphs of each gesture were made where the number of correct answers is detailed according to the session that the children performed (Figures 22- 29).

In Fig. 22, it is observed that from session 3 there is a general improvement in the perception of the YES gesture. Patients 1 and 2 managed to get 5 out of 5 attempts right at the end of the 6 sessions, while patients 3 and 4 managed to obtain 3 correct answers at the end of the 4 sessions.

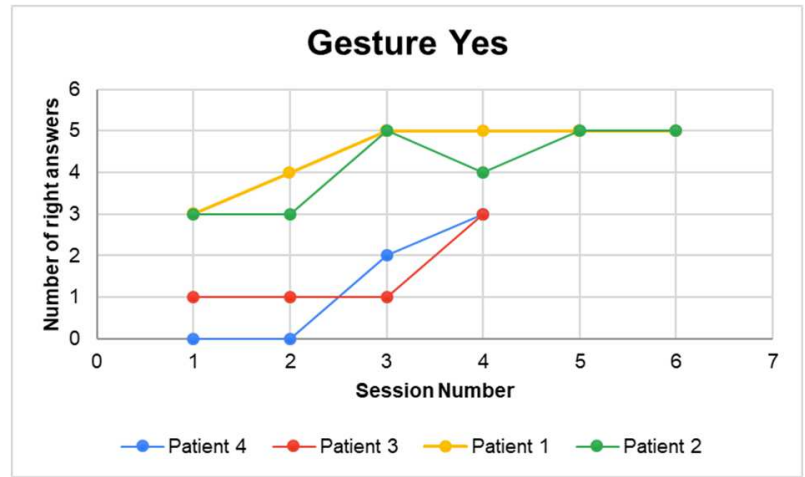

Fig. 22 Results Question 1

In Fig. 23, it is observed that from session 2 there is a general improvement in the perception of the NO gesture. Patients 1 and 2 managed to get 5 out of 5 attempts right at the end of the 6 sessions, while patients 3 and 4 managed to obtain 3 and 2 correct answers respectively at the end of the 4 sessions.

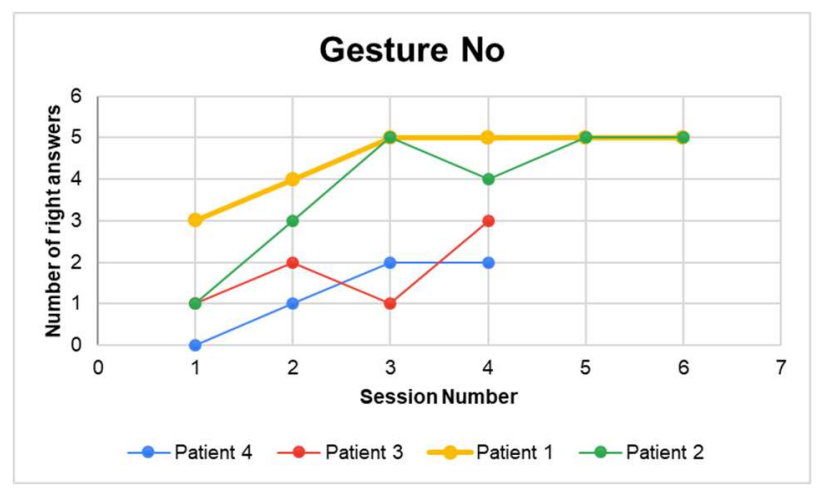

Fig. 23 Results Question 2

In Fig. 24, it is observed that from session 2 there is a general improvement in the perception of the Crying gesture. Patients 1 and 2 managed to get 5 out of 5 attempts right at the end of the 6 sessions, while patients 3 and 4 managed to obtain 2 and 3 correct answers respectively at the end of the 4 sessions.

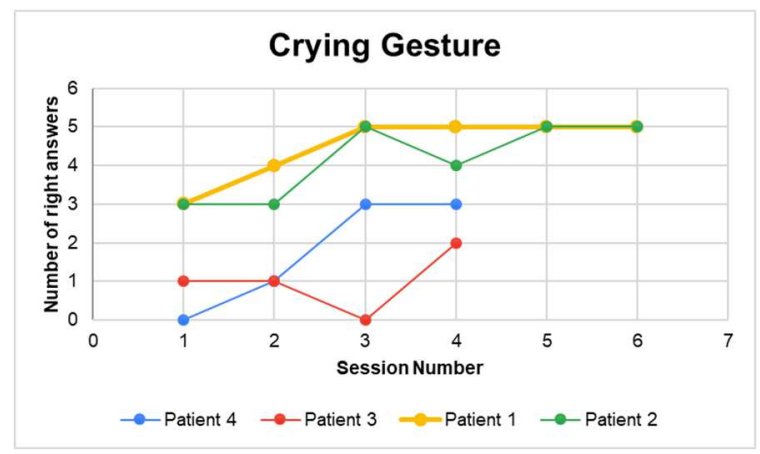

Fig. 24 Results Question 3

In Fig. 25, it is observed that from session 3 there is a general improvement in the perception of the SCARED gesture. patients 1 and 2 managed to get 5 out of 5 attempts right at the end of the 6 sessions, while patients 3 and 4 managed to obtain 2 and 3 correct answers respectively at the end of the 4 sessions. 


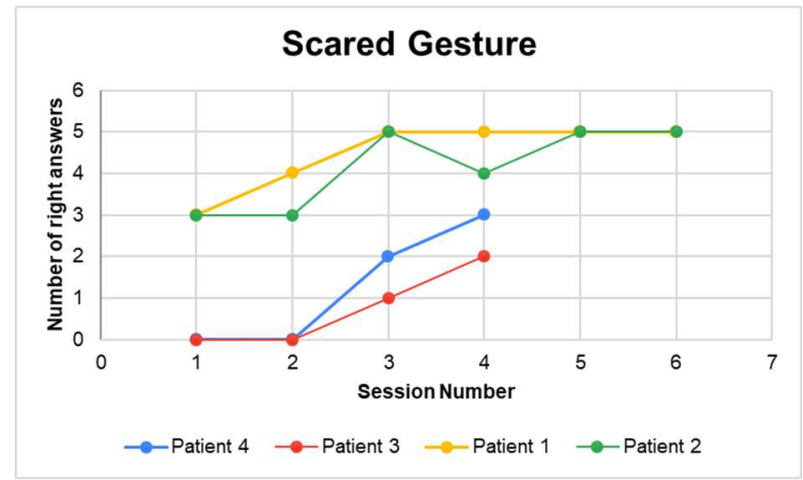

Fig. 25 Results Question 4

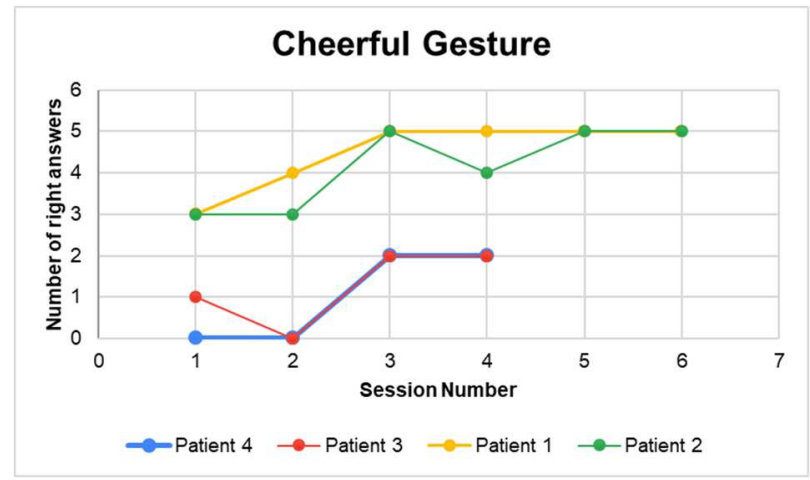

Fig. 26 Results Question 5

In Fig. 26, it is observed that from session 3 there is a general improvement in the perception of the CHEERFUL gesture. Patients 1 and 2 managed to get 5 out of 5 attempts right at the end of the 6 sessions, while patients 3 and 4 managed to obtain 3 right answers at the end of the 4 sessions.

In Fig. 27, it is observed that from session 2 there is a general improvement in the perception of the POINT gesture. Patients 1 and 2 managed to get 5 out of 5 attempts right at the end of the 6 sessions, while patients 3 and 4 managed to obtain 4 and 1 correct answers respectively at the end of the 4 sessions. The patients had difficulty with this gesture because in some sessions they confused the point gesture with greet gesture.

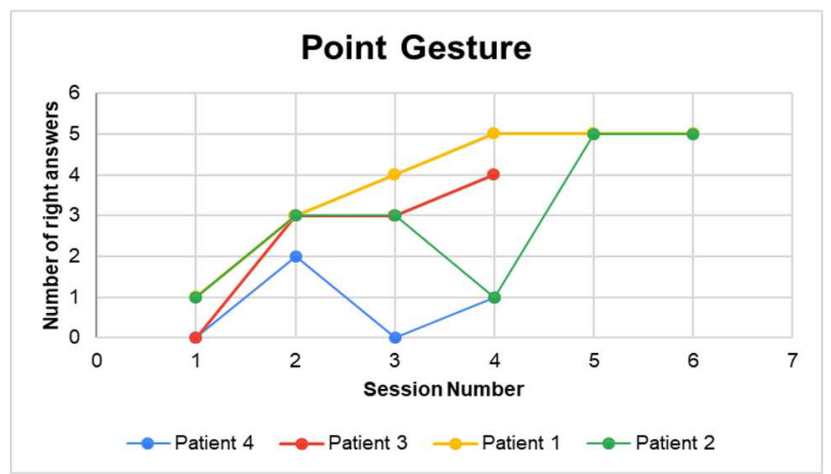

Fig. 27 Results Question 6

In Fig. 28, it is observed that from session 3 there is a general improvement in the perception of the gesture GREET. Patients 1 and 2 managed to get 5 out of 5 attempts right at the end of the 6 sessions, while patients 3 and 4 managed to obtain 5 and 3 correct answers respectively at the end of the 4 sessions, observing an improvement in the perception of the gesture GREET.

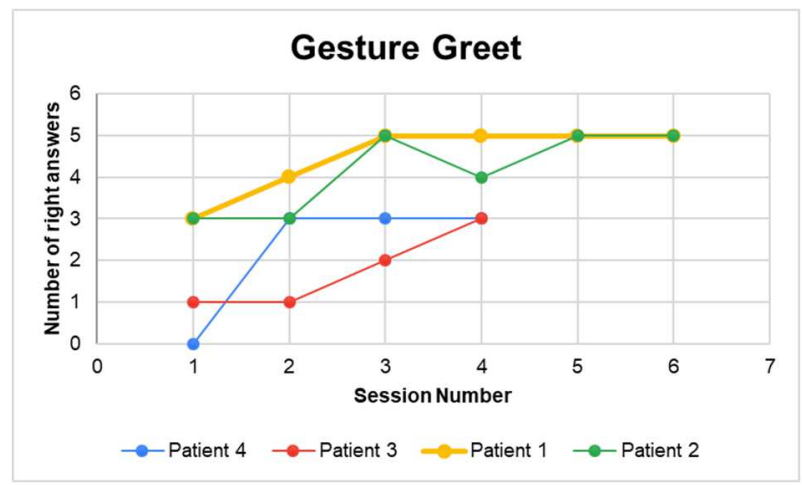

Fig. 28 Results Question 7

In Fig. 29, it is observed that patients 1 and 2 managed to get 4 out of 5 attempts right at the end of the 6 sessions, while patients 3 and 4 failed to obtain correct answers at the end of the 4 sessions. In Calm gesture an improvement in patients 3 and 4 could not be detected, because patients 3 and 4 are younger than patients 1 and 2 , which makes it difficult for them to understand the quiet gesture, and the robot does not perform pronounced movements in this gesture.

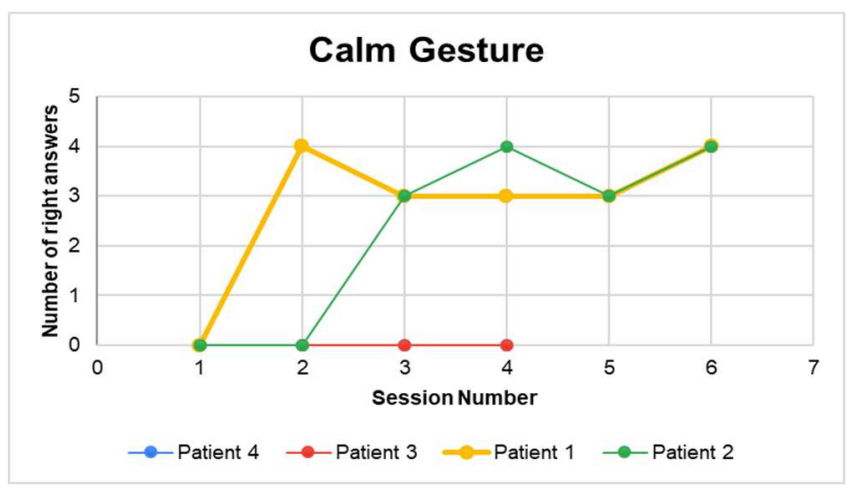

Fig. 29 Results Question 8

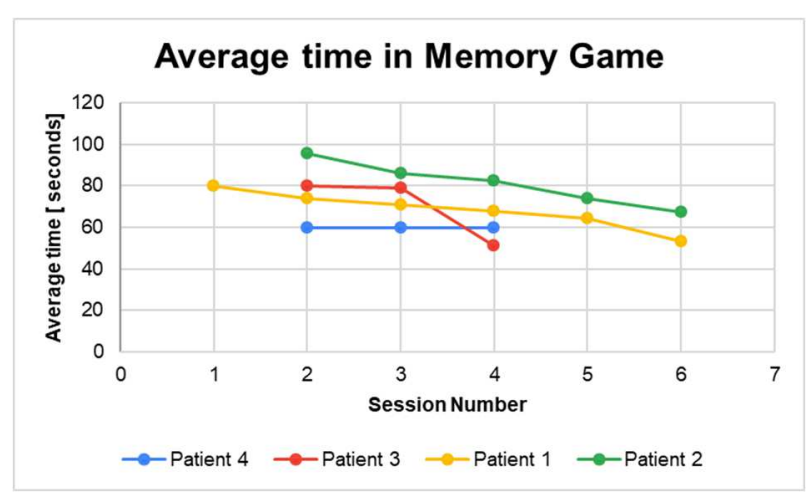

Fig. 30 Results Question 10

In each session the children performed 5 repetitions of the memory game. In item 10 of the survey, therapists are asked to indicate the amount of time it took the children to find a certain number of pairs. In the case of patient 1 and patient 2 , the amount of time it took them to find 6 pairs of cards, while, for patient 3 and patient 4 , the amount of time it took them to find 2 pairs of cards. Fig. 30 shows the line graph of the average time it takes the children to complete the memory game in each session. 
Table 7 shows the average percentage of progress of the patients according to each gesture. Obtaining an average percentage of general progress in gesture recognition of $45 \%$, at the end of all sessions.

TABLE VII

Percentage of Progress at the End of the Sessions of EACH ChILD

\begin{tabular}{ccccccc}
\hline Q. & $\begin{array}{c}\text { Patient } \\
\mathbf{1}\end{array}$ & $\begin{array}{c}\text { Patient } \\
\mathbf{2}\end{array}$ & $\begin{array}{c}\text { Patient } \\
\mathbf{3}\end{array}$ & $\begin{array}{c}\text { Patient } \\
\mathbf{4}\end{array}$ & Avg. & $\begin{array}{c}\text { Std. } \\
\text { Dev. }\end{array}$ \\
\hline 1 & 40 & 40 & 40 & 60 & 45 & 10 \\
2 & 40 & 80 & 40 & 40 & 50 & 20 \\
3 & 40 & 40 & 20 & 40 & 35 & 10 \\
4 & 40 & 40 & 20 & 40 & 35 & 10 \\
5 & 40 & 40 & 20 & 40 & 35 & 10 \\
6 & 80 & 80 & 80 & 20 & 65 & 30 \\
7 & 40 & 40 & 40 & 60 & 45 & 10 \\
8 & 100 & 100 & 0 & 0 & 50 & 57.73 \\
10 & 28.75 & 36 & 27.5 & 0 & 23.06 & 15.82 \\
\hline
\end{tabular}

It can be recommended for later works to improve gestures that did not have an impact on the children, making them more expressive or changing them to gestures that are easier to recognize, that was the case of the calm gesture. It is also recommended to increase the screen size so that patients are able to see the images clearly in each of the games. Finally, it is recommended to personalize each game according to the needs of each child with the help of the therapists, either by implementing different images or different gestures to seek to improve specific problems in each patient.

\section{CONCLUSION}

KERO is a Playable kit with two games to develop memory and gesture recognition, designed and implemented as a support tool in the development of non-verbal communication skills of children with ASD in ages 4 to 7 years. The tool was validated in preliminary tests and field tests, which indicate that children adapt more easily to a wireless controller because they are familiar with smartphones and similar devices. The presentation of an alternative means of handling the robot, such as modeling clay, did not positively impact the therapies since it became a distraction that prevented the child from interacting with the robot and meeting the session's objectives.

Once the sessions with the target population have been completed. It can be concluded that the KERO Playable KIT contributes, during therapy, to the interaction between the therapist and the child. Since it is not invasive, it allows creating an environment of curiosity and trust with the therapist. In addition, an improvement was observed in the recognition of gestures by children with autism, with the exception of the calm gesture, which is recommended to change to another one or modify it to make it easier to recognize. The child who showed the greatest progress during the sessions was patient 2 , who, after performing six sessions, managed to imitate most of the gestures and exclamations made by the robot through the movement of his body.

As an analysis of the results, it can be concluded that there is an average improvement of $23.06 \%$. The decrease in the amount of time to execute the memory games because they adapted to the game's dynamics and controlled the robot more easily and with confidence throughout the sessions. It could also be concluded that the children improved their ability to recognize gestures. Based on the evaluations carried out during the sessions, an average improvement percentage of $45 \%$ was obtained. The results obtained in each session depend on certain factors such as the predisposition that each child has to work and the constancy with which they attended the therapies, for which in some sessions there are setbacks in the results of each child.

\section{REFERENCES}

[1] H. Javed, R. Burns, M. Jeon, A. M. Howard, and C. H. Park, “A robotic framework to facilitate sensory experiences for children with autism spectrum disorder: A preliminary study," arXiv, vol. 9, no. 1. arXiv, pp. 1-26, Jan. 03, 2019.

[2] R. Suzuki, J. Lee, and O. Rudovic, "NAO-dance therapy for children with ASD," in ACM/IEEE International Conference on Human-Robot Interaction, Mar. 2017, pp. 295-296.

[3] E. Alarfaj, H. Alabdullatif, H. Alabdullatif, G. Albakri, and N. S. A. Karim, "Analysis of the use of a nao robot to improve social skills in children with ASD in Saudi Arabia," in Advances in Intelligent Systems and Computing, Sep. 2018, vol. 868, pp. 902-913.

[4] A. Stahmer, L. Schreibman, A. C.-B. research, and undefined 2011, "Toward a technology of treatment individualization for young children with autism spectrum disorders," Elsevier, Accessed: Dec. 01, 2020. [Online]. Available: https://www.sciencedirect.com/science/article/pii/S00068993100204 82.

[5] C. L. van Straten, I. Smeekens, E. Barakova, J. Glennon, J. Buitelaar, and A. Chen, "Effects of robots' intonation and bodily appearance on robot-mediated communicative treatment outcomes for children with autism spectrum disorder," Pers. Ubiquitous Comput., vol. 22, no. 2, pp. 379-390, Apr. 2018

[6] L. Boccanfuso, S. Scarborough, R. K. Abramson, A. V. Hall, H. H Wright, and J. M. O'Kane, "A low-cost socially assistive robot and robot-assisted intervention for children with autism spectrum disorder: field trials and lessons learned," Auton. Robots, vol. 41, no. 3, pp. $637-$ 655, Mar. 2017

[7] B. Scassellati et al., "Improving social skills in children with ASD using a long-term, in-home social robot," 2018. Accessed: Dec. 01, 2020. [Online]. Available: http://robotics.sciencemag.org/.

[8] P. Esteban, P. Baxter, T. Belpaeme, E. B.- Paladyn, J. of, and undefined 2017, "How to build a supervised autonomous system for robot-enhanced therapy for children with autism spectrum disorder," degruyter.com, Accessed: Nov. 27, 2020. [Online]. Available: https://www.degruyter.com/view/journals/pjbr/8/1/article-p18.xml.

[9] F. Petric and Z. Kovacic, "Design and Validation of MOMDP Models for Child-Robot Interaction Within Tasks of Robot-Assisted ASD Diagnostic Protocol," Int. J. Soc. Robot., vol. 12, no. 2, pp. 371-388, May 2020.

[10] S. Ali, F. Mehmood, D. Dancey, Y. Ayaz, ... M. K.-I., and undefined 2019, "An adaptive multi-robot therapy for improving joint attention and imitation of ASD children," ieeexplore.ieee.org, Accessed: Nov. 27, 2020. [Online]. Available: https://ieeexplore.ieee.org/abstract/document/8740865/.

[11] C. Huijnen, M. Lexis, ... R. J.-J. of A. and, and undefined 2019, "Roles, strengths and challenges of using robots in interventions for children with autism spectrum disorder (ASD)," Springer, Accessed: Dec. 01, 2020. [Online]. Available: https://ink.springer.com/content/pdf/10.1007/s10803-018-3683x.pdf.

[12] F. Petric, D. Miklić, and Z. Kovačić, "POMDP-based coding of childrobot interaction within a robot-assisted ASD diagnostic protocol," Int J. Humanoid Robot., vol. 15, no. 2, Apr. 2018.

[13] R. N. Choueiri and A. W. Zimmerman, "New Assessments and Treatments in ASD," Current Treatment Options in Neurology, vol. 19, no. 2. Current Science Inc., pp. 1-18, Feb. 01, 2017.

[14] B. Tleubayev, Z. Zhexenova, A. Zhakenova, and A. Sandygulova, "Robot-assisted therapy for children with ADHD and ASD: A pilot study," in ACM International Conference Proceeding Series, Mar. 2019, pp. 58-62.

[15] D. Damianidou, A. Eidels, and M. Arthur-Kelly, "The Use of Robots in Social Communications and Interactions for Individuals with ASD: a Systematic Review," Adv. Neurodev. Disord., vol. 4, no. 4, pp. 357 388 , Nov. 2020 
[16] J. A. Vlachou and A. S. Drigas, "Mobile Technology for Students \& Adults with Autistic Spectrum Disorders (ASD)," Int. J. Interact. Mob. Technol., vol. 11, no. 1, pp. 4-17, Jan. 2017.

[17] D. Silvera-Tawil, D. Bradford, and C. Roberts-Yates, "Talk to Me: The Role of Human-Robot Interaction in Improving Verbal Communication Skills in Students with Autism or Intellectual Disability," in RO-MAN 2018 - 27th IEEE International Symposium on Robot and Human Interactive Communication, Nov. 2018, pp. 1196-1201.

[18] N. Giullian, D. Ricks, A. Atherton, M. Colton, M. Goodrich, and B. Brinton, "Detailed requirements for robots in autism therapy," in 2010 IEEE International Conference on Systems, Man and Cybernetics, Oct. 2010, pp. 2595-2602.
[19] K. Dautenhahn and I. Werry, "Towards interactive robots in autism therapy: Background, motivation and challenges," Pragmatics \& Cognition, vol. 12, no. 1, pp. 1-35, Jan. 2004.

[20] K. F. MacDorman, R. D. Green, C.-C. Ho, and C. T. Koch, "Too real for comfort? Uncanny responses to computer generated faces," Computers in Human Behavior, vol. 25, no. 3, pp. 695-710, May 2009.

[21] S. Farah, D. G. Anderson, and R. Langer, "Physical and mechanical properties of PLA, and their functions in widespread applications A comprehensive review," Advanced Drug Delivery Reviews, vol. 107, pp. 367-392, Dec. 2016.

[22] A. Joshi, S. Kale, S. Chandel, and D. K. Pal, "Likert Scale: Explored and Explained," Current Journal of Applied Science and Technology, pp. 396-403, Feb. 2015. 